\title{
ORAL ADMINISTRATION OF RAW WHITE KIDNEY BEANS (PHASEOLUS VULGARIS L. VAR. BELDIA) INDUCES OVERGROWTH OF FECAL COLIFORMS AND LACTOBACILLI IN WISTAR RATS
}

\author{
NADER NCIRI ${ }^{1,2,3}$, TAESUB SHIN ${ }^{3}$, NAMJUN CHO ${ }^{3 *}$ \\ ${ }^{1}$ Intestinal Immunophysiology-Research Unit (02/RU/09-02), Faculty of Medicine of Tunis, University of Tunis El Manar, Bab Saâdoun, \\ Tunis, Tunisia. ${ }^{2}$ Department of Animal Resources, Fisheries and Food Technology, National Institute of Agronomy of Tunisia, El Mahrajène, \\ Tunis, Tunisia. ${ }^{3}$ School of Energy, Materials and Chemical Engineering, Korea University of Technology and Education, Cheonan, \\ Chungnam, Republic of Korea. Email: njuncho@koreatech.ac.kr \\ Received: 11 September 2017, Revised and Accepted: 11 October 2017
}

\section{ABSTRACT}

Objective: The comprehensive dynamics of fecal microbiota in response to the ingestion of toxic bean lectins or phytohemagglutinins has not been well studied. The study aimed at evaluating the gavage effects of a raw Beldia bean variety on food intake, growth performance, gastrointestinal organs, and fecal microflora in Wistar rats.

Methods: Twenty young adult male rats were randomly allotted into two groups of 10 rats each: Control rats were gavaged with 300 mg of a rodent pellet flour suspension and experimental rats were orogastrically fed a dose of $300 \mathrm{mg}$ Beldia bean flour suspension (BBFS). Individual food intake, body weight, and fecal score were taken daily. To assess the impact on the gut flora, fecal samples were collected every day for 10 days. All animals were sacrificed on day 10, to obtain blood and internal organs samples.

Results: The results revealed that the gavage of a BBFS to rats had no marked influence on average daily of food intake and weight gain. No significant differences were found in the weights of the small intestine, spleen, liver, and thymus of rats given raw Beldia diet. The counts of coliforms and lactobacilli on pooled fecal specimens of BBFS-fed rats were increased significantly compared to controls.

Conclusion: In summary, the exposure to raw Beldia beans altered the fecal microbiota, without adverse effects on animals.

Keywords: Body weight, Coliforms, Fecal microflora, Food intake, Internal organs, Lactobacilli, Phytohemagglutinin, White kidney bean (Phaseolus vulgaris L.).

(c) 2018 The Authors. Published by Innovare Academic Sciences Pvt Ltd. This is an open access article under the CC BY license (http://creativecommons. org/licenses/by/4. 0/) DOI: http://dx.doi.org/10.22159/ajpcr.2018.v11s3.30036

\section{INTRODUCTION}

Legumes, soybeans, and common beans, in particular, are vital sources of protein in many developed and developing countries. In addition to being eaten raw in salads, they are also consumed in cooked form in several dishes including casseroles, macaroni, and Rajma-chawal. They are also utilized in the preparation of rations and texturized protein concentrates for animal consumption. An undesirable occurrence was the discovery of various antinutritional factors in legume seeds such as lectins, protease inhibitors, saponins, phytic acid, and tannins whose mechanism of action is still poorly defined and poorly understood. One of these factors is phytohemagglutinin (PHA), the heat-stable lectin from the kidney bean (Phaseolus vulgaris L.; Family: Fabaceae) [1], which, when ingested orally, results in diarrhea, impaired nutrition absorption, growth rate inhibition, and can even lead to the eventual death of PHA-fed animals [2,3]. These effects are believed to result from changes in the autochthonous microflora induced by the presence of PHA in the diet [2,4-7]. Information is accumulating on the effects of PHA on intestinal microflora, but there is a marked lack of information regarding the significance of these effects on fecal microbiota. It was decided, therefore, to examine the influence of a raw Beldia bean gavage on the food intake, body growth, weight of internal organs, and fecal microflora (namely, coliforms and lactobacilli) in Wistar rats.

\section{METHODS}

\section{Plant materials}

The common white beans ( $P$. vulgaris L.), variety Beldia, were purchased in March 2017 from a local market in Ariana city, Tunis, Tunisia.
The seeds were cleaned manually to remove all foreign materials such as dust, dirt, stones, and broken seeds. The plant material was characterized and authenticated at the Department of Botany, the National Agricultural Research Institute of Tunisia, Ariana, Tunis, Tunisia. The beans were aseptically ground dry with a sterile mortar and pestle and then passed through the US Standard No. 200 sieve (75 $\mu \mathrm{m})$. The powder was packed, sealed in polyethylene bags, and stored in a cold room at $4^{\circ} \mathrm{C}$. The fine flour thus obtained was used in the feeding studies and in the preparation of crude Beldia bean extract (CBBE).

\section{Experimental design, animals, and housing}

Twenty young Wistar male rats (Rattus norvegicus albinus; specified pathogen-free), weighting $60 \sim 80 \mathrm{~g}$, were initially acclimatized for 7 days and were used in this study. Rattus albinus was purchased from the Pasteur Institute of Tunis, Tunis, Tunisia, kept singly in sterile polypropylene cages on chopped aspen wood bedding, and maintained in a well-ventilated, thermostatically controlled room $\left(25 \pm 1.4^{\circ} \mathrm{C}\right)$ with $12 \mathrm{~h}$ light and $12 \mathrm{~h}$ dark (from $8 \mathrm{am}$ to $8 \mathrm{pm}$ ) cycles. They were fed with a good quality pellet diet from Cereal Office, Tunis, Tunisia. The water was allowed ad libitum. The proximate composition of the daily feed offered to rats was determined by the Food Technology Service (STA), National Institute of Nutrition and Food Technology, Tunis, Tunisia, according to AOAC [8]. $100 \mathrm{~g}$ of dry rodent pellets (deprived of lectins) contained about $12.77 \%$ protein, $2.52 \%$ lipid, $69.18 \%$ carbohydrate, and $350 \mathrm{Kcal}$ energy. Rats were handled daily by the same investigator and were fasted overnight $(15 \mathrm{~h})$ with free access to water before the experiment. Animals were monitored during the study for clinical signs, mortality, feed intake, body weight and body weight gain, and feces 
bacteriology. The rats were randomly assigned to two groups of ten rats each and were treated daily for 10 days as follows: Group 1 was daily administered with a single dose of a $300 \mathrm{mg}$ rodent pellet flour (lectinfree), suspended in $3 \mathrm{ml}$ distilled water rodent pellet flour suspension (RPFS), by oral intubations using gavage needle, and served as control. Group 2 was orally intubated (by gavage needle) with a $300 \mathrm{mg}$ Beldia bean flour mixed with $3 \mathrm{ml}$ distilled water Beldia bean flour suspension (BBFS) and served as experimental [4,9-11]. This research has the approval of the Ethics Committee for the Use of Laboratory Animals of the Faculty of Medicine of Tunis and followed the Council of International Organization of Medical Sciences ethical code for animal experimentation.

\section{Collection of blood samples and organs}

At the end of the test period (day 10), the rats were anesthetized by diethyl ether (PARAPHARM, Athens, Greece) before sacrifice by exsanguination. The abdomen and thorax were then opened immediately, and blood (ca. 0.5 1.0 ml) was collected through cardiac puncture using sterile syringes and needles, emptied into plain tubes, and allowed to clot for about $2 \mathrm{~h}$ (Fig. 1). The clotted blood was thereafter centrifuged at $3500 \mathrm{rpm}$ for $30 \mathrm{~min}$ to recover serum from clotted blood. Serum was separated with sterile syringes and needles and stored at $-70^{\circ} \mathrm{C}$ until used for hemagglutination assay (HA). After this, the small intestine, from the pylorus to the ileocecal junction, was removed, placed on a non-absorbent surface, and weighted. Finally, the small intestine (after opening and rinsing with ice-cold saline to remove its contents), spleen, liver, and thymus were promptly dissected out and weighted.

\section{HA}

In the present study, the sera collected from raw Beldia beans-fed rats were screened for lectin activity. The assay of hemagglutination was carried out in small glass tubes. At day 10 and after $3 \mathrm{~h}$ (i.e., time required for $P$. vulgaris lectins to reach the systemic circulation of animals) of gavage with BBFS, the sera were collected and serially diluted (e.g., 1/1, 1/2, 1/4, 1/8, 1/16, 1/32, 1/64, 1/128, 1/256, $1 / 512$, and $1 / 1024 ; 0.1 \mathrm{ml})$ with sterile saline $(0.9 \%$ sodium chloride $[\mathrm{NaCl}])$, and each dilution was tested for erythrocyte agglutination by mixing the serum extract with a $2 \% \mathrm{O}^{+}$human erythrocyte suspension ( $0.1 \mathrm{ml}$; Blood banks, Hospital Charles Nicolle, Tunis, Tunisia). The degree of agglutination was monitored visually at room temperature (ca. $25^{\circ} \mathrm{C}$ ) for $2 \mathrm{~h}$, as the highest dilution of the extract showed visible agglutination. The content of each tube was also confirmed microscopically. Negative control was prepared using only phosphatebuffered saline and erythrocytes suspension. The positive control was prepared using commercially available purified PHAs (Sigma-Aldrich, Lesquin, France) and erythrocytes suspension. All experiments were conducted in triplets.

\section{Bacteriological examination}

The procedure of Ellinger et al. [12] was applied to collect fecal samples over 10 days to enumerate fecal coliforms and lactobacilli. The samples were collected, approximately at 8:30 am, fresh by gently squeezing the rectal area of the rat, into sterile $50 \mathrm{ml}$ Falcon Tubes (Biosphère, Tunis, Tunisia) and then transported immediately to the bacteriology department, faculty of medicine of Tunis. A subsample (about $1 \mathrm{~g}$ ) of the feces was placed in a $50 \mathrm{ml}$ Falcon Tube and mixed with $9 \mathrm{ml}$ of physiological saline water. The mixture was vortexed for $2 \sim 3$ min until homogenous. Bacterial enumeration was carried out using selective growth media and growth conditions. Each fecal sample (1 g) was serially diluted 10 -fold with $9 \mathrm{ml}$ of sterilized saline water (SIPHAT, Tunis, Tunisia) dilution from $10^{-1}$ to $10^{-9}$. From each dilution, $100 \mu \mathrm{l}$ of suspension was plated out, in duplicate on the MRS agar (De Man-Rogosa Shape Agar, BIOKAR Diagnostics, Allonne, France) and MacConkey agar (BIOKAR Diagnostics, Allonne, France) for the determination of the total cell count of Lactobacillus spp. and coliforms, respectively $[5,11]$. The MRS broth agar plates were incubated anaerobically at $37^{\circ} \mathrm{C}$ for $48 \mathrm{~h}$. Petri dishes that had 30-300 colonies were counted. MacConkey agar plates were incubated aerobically at $37^{\circ} \mathrm{C}$ for $24 \mathrm{~h}$. All red colonies were recorded in the countable range 15-150 colonies. The colonies were counted, and bacteria were Gram stained in a light microscope. The viable counts were expressed as the $\log _{10}$ of colony-forming units (CFU)/g of feces.

\section{Statistical analysis}

Results are expressed as means \pm standard error mean (SEM). Student's $t$-test was used to determine the significance of the differences between the means of the values obtained from the experiment rat group and those obtained from the control rat group. Statistical significance was established at $\mathrm{p}<0.05$.

\section{RESULTS}

\section{Food intake behavior}

The daily food intake of animals was determined by difference between weights of food supplied every day and the remnant in the feeder $24 \mathrm{~h}$ later. Referring to Fig. 2, daily food intake was similar in rats treated with RPFS and in rats gavaged with BBFS ( $p>0.05)$, with a mean value of food consumption of $19.30 \pm 1.13$ and $18.26 \pm 1.14 \mathrm{~g} / \mathrm{rat} /$ day, for control and experimental groups, respectively.

\section{Growth performance}

Rats' weights in all groups were recorded once per day since the beginning of treatments. The growth profile of the rats fed with the different diets is displayed in Fig. 3. No adverse effect of BBFS on experimental rats was detected. No statistically significant differences ( $p>0.05$ ) between groups were observed during the experiment when data of body weight were analyzed. At day 1 , mean body weight was $70.05 \pm 7.27 \mathrm{~g}$ in control rats (range $62-82.2 \mathrm{~g}$ ) and $74.1 \pm 6.72 \mathrm{~g}$ in experimental rats (range 61.8-83 g). At the end of the study (day 10), the mean body weight recorded in control rats was $92.5 \pm 12.09$ (74-112 g) and in experimental rats was $96.6 \pm 9.99 \mathrm{~g}(74-111 \mathrm{~g})$. The average daily gain (growth rate) at the end of 10 days was $2.2 \mathrm{~g} /$ day in control rats and $2.25 \mathrm{~g} /$ day in experimental rats, and no statistically significant differences $(p>0.05)$ were noted. BBFS-treated animals appeared clinically normal, and no death was recorded.

\section{Internal organ weights}

The weights of the various organs of control and experimental rats are summarized in Table 1. As can be observed, no obvious differences in the weights of the internal organs were found. 10 days of treatments with BBFS had no significant effect on the small intestine, spleen, liver, and thymus weights of the investigated rats (Fig. 4, p>0.05).

\section{HA}

The HA obtained with human blood Group 0 at various dilutions of serum extract samples collected from experimental rats are condensed in Table 2. None of the serum dilutions showed any specificity toward the red blood cells, ehereas, these latter were clumped by the commercially available purified PHAs (Sigma-Aldrich, Lesquin, France) and the CBBE. Initially, these findings suggest the absence of $P$. vulgaris agglutinins in the systemic circulation of BBFS-fed rats. However, further investigation should be undertaken to confirm this presumption.

\section{Bacteriological studies}

The fecal materials collected from control and experimental rats were normal and solid softer. The concentration of coliforms and lactobacilli in feces was monitored for up to 10 days (Fig. 5). Preliminary examination of Figs. 6 and 7 reveals that the numbers of coliforms and lactobacilli in the feces differ significantly among groups of rats treated with RPFS or BBFS $(p<0.05)$. There was also a trend in the increase of numbers of these microorganisms over the 10-day experimental period. This instability observed for the experimental rats probably represents the abnormal development of the small intestinal microflora in these animals.

\section{Counts of coliforms}

Fig. 6 depicts the counts of the coliform populations in control and experimental rats. In feces collected from individual rats that received 

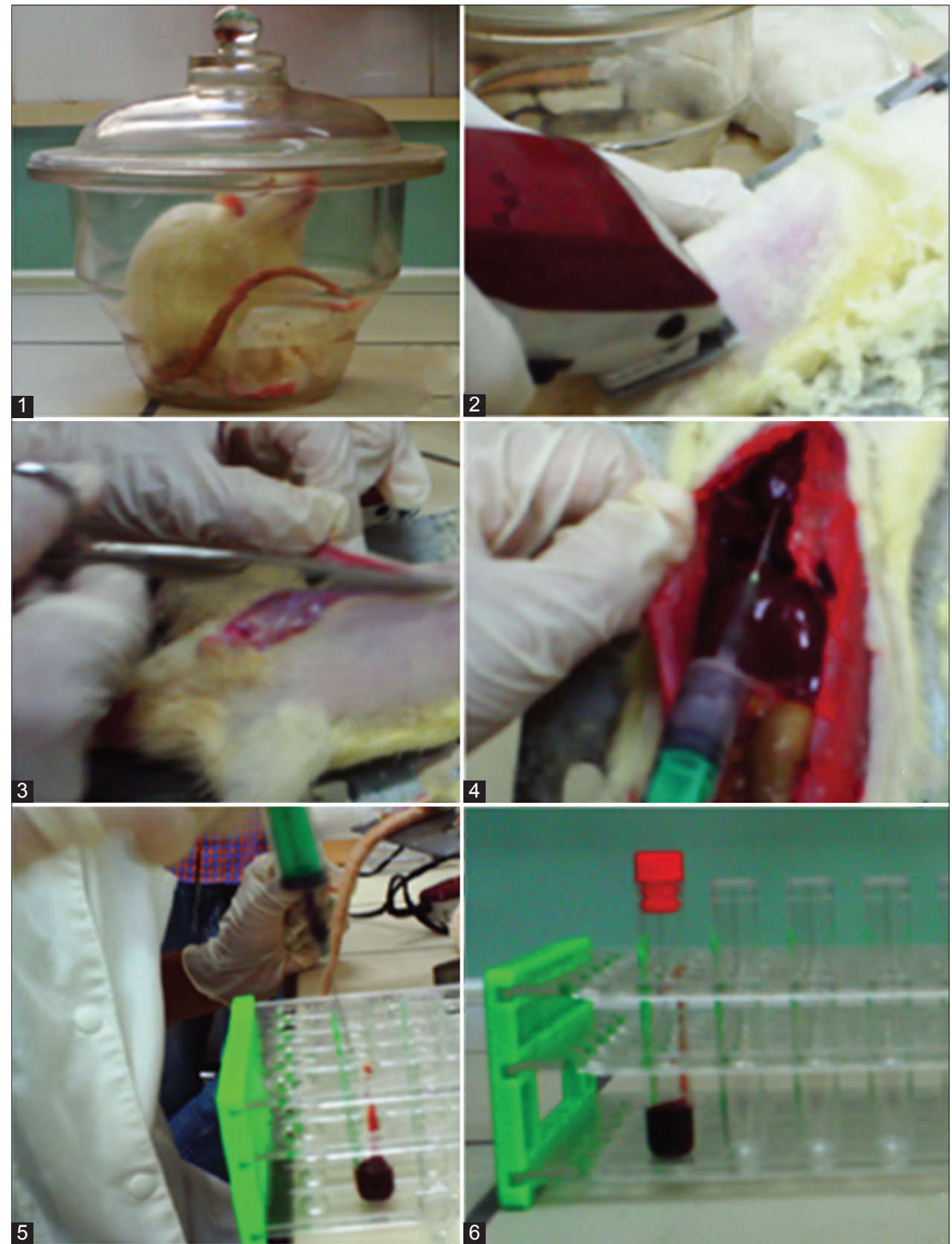

Fig. 1: Blood sample collection from Wistar rat gavaged with Beldia bean flour suspension at the dose of $300 \mathrm{mg} / \mathrm{day}$ for $10 \mathrm{days}$.(1) Ether anesthesia (5 min); (2) Shaving the hairs over the abdomen-thorax area and treatment with antiseptic (70\% alcohol); (3) Dissection of the thoracic and abdominal cavities; (4) Cardiac puncture under ether anesthesia; (5) Pouring the blood into a collection tube;

(6) Collection of blood into plain tube

RPFS, the $\log _{10} \mathrm{CFU} / \mathrm{g}$ feces for coliform bacteria was $3.26 \pm 0.82$ (range 2.1-4.54) at day 1 and 3.57 \pm 0.48 (range 3.01-4.23) at day 10 . The rats fed by gavage $300 \mathrm{mg}$ BBFS had levels of coliform bacteria $3.33 \pm 0.72$ (range 2.18-4.36) and 4.49 $\pm 0.54 \log _{10} \mathrm{CFU} / \mathrm{g}$ feces (range 3.78-5.35), at days 1 and 10, respectively. As noticed, BBFS altered significantly the level of coliform in these animals $(\mathrm{p}<0.05)$.

\section{Counts of lactobacilli}

As can be seen in Fig. 7, compared to control rats, a significant change $(\mathrm{p}<0.05)$ in numbers of lactobacilli was found in rats gavaged with $300 \mathrm{mg}$ BBFS. In control rats, when animals were orogastrically intubated with $300 \mathrm{mg}$ RPFS, the mean fecal lactobacillus microbial counts at day 1 were $8.46 \pm 0.82 \log _{10} \mathrm{CFU} / \mathrm{g}$ feces (range 7.09-9.81 $\log _{10} \mathrm{CFU} / \mathrm{g}$ feces) and at day 10 were $8.40 \pm 0.99 \log _{10} \mathrm{CFU} / \mathrm{g}$ feces (range 7.01-9.75 $\log _{10}$ $\mathrm{CFU} / \mathrm{g}$ feces). In experimental rats, when the diet was raw Beldia beans, the mean fecal lactobacillus microbial counts at day 1 were $8.34 \pm 1.51$ $\log _{10} \mathrm{CFU} / \mathrm{g}$ feces (range 6.18-10.9 $\log _{10} \mathrm{CFU} / \mathrm{g}$ feces) and at day 10 were $10.95 \pm 0.62 \log _{10}$ CFU/g feces (range 10.33-12.33 $\log _{10} \mathrm{CFU} / \mathrm{g}$ feces).

\section{DISCUSSION}

The current study investigated the impact of raw Beldia kidney beans on health parameters of rats such as feed intake, weight body, internal organs weights, and fecal microflora. In this experiment, no mortality or clinical signs of disease of any rats of both groups were recorded. There were no gross changes in food intake and body weight in the rats gavaged daily with $300 \mathrm{mg} \mathrm{BBFS}$, in comparison with the rats received $300 \mathrm{mg}$ RPFS over the course of 10 days. To give a scientific explanation of the different findings achieved using raw beldia beans, most of the toxicologists suggest that the manifestation of bean toxicity depends on many factors such as experimental animal species used for testing, animal age and sex, administration route, administration 


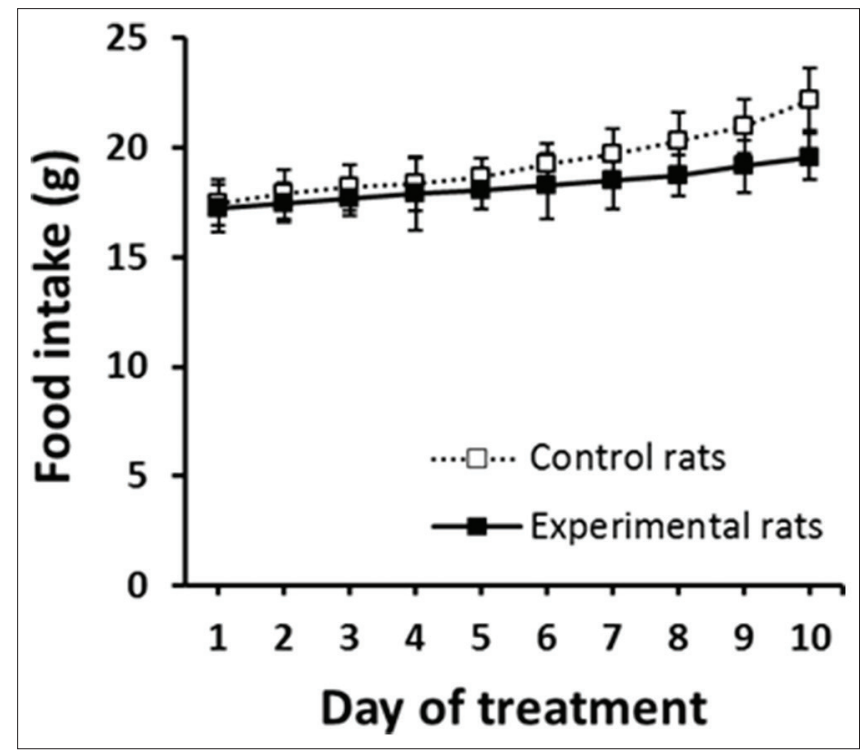

Fig. 2: Food intake curves of Wistar rats. In the control group, rats were gavaged with RPFS at the dose of $300 \mathrm{mg} / \mathrm{rat} / \mathrm{day}$ for 10 days. In the experimental group, rats were gavaged with BBFS at the same dose $(300 \mathrm{mg} / \mathrm{rat} / \mathrm{day})$ for 10 days (mean \pm standard error of the mean of 10 rats)

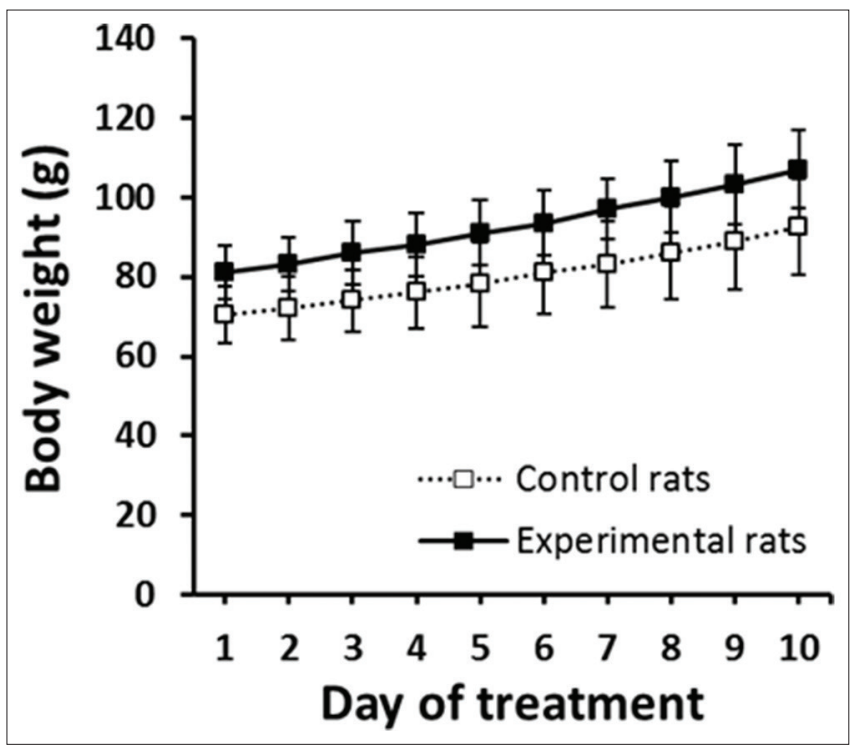

Fig. 3: Growth curves of Wistar rats. In the control group, rats were gavaged with RPFS at the dose of $300 \mathrm{mg} / \mathrm{rat} / \mathrm{day}$ for 10 days. In the experimental group, rats were gavaged with BBFS at the same dose $(300 \mathrm{mg} / \mathrm{rat} /$ day) for 10 days (mean \pm standard error of the mean of 10 rats)

levels, timing of treatment, variety of beans, overall diet composition, and environmental factors. The similar conclusion can be drawn for the addition of purified PHA in rat feed. Many experiments investigate the effect of kidney beans on rats' performance yielded contradicting results. Some of the authors reported a toxic effect of raw beans on rat performance, while in other trials, different varieties of beans did not affect the feed intake and body weight gain in rats.

The effects of kidney beans on food intake of rats in this trail are in disagreement with large number of studies which have shown the effects of using purified PHA and extract or ground beans. For example, in a series of experiments conducted by Fantini et al. [13] to obtain information on the etiology of "kidney bean toxicosis," it was found that administration of doses of $P$. vulgaris dry extract, devoid of any behavioral toxicity dose-dependently, decreased markedly diet consumption in rats. In other investigation done by Marzo et al. [14] looked at the effects of extruded kidney bean (P. vulgaris L. var. "Pinto") on growth and skeletal muscle nitrogen fractions in rats; it was discovered that the feed intake of animals fed with raw var. "Pinto" ( $94.7 \mathrm{~g} / 100 \mathrm{~g}$ body weight) during 8 days was remarkably reduced compared to control (65.5 g/100 g body weight). In 1988, Lafont et al. [15] administered purified PHA for 9 days to growing rats at levels ranging from $0.0025 \%$ to $0.25 \%$ of food dry matter. They noticed that PHA reduced the food intake when offered at a level higher than $0.04 \%$. Baintner et al. [16] tested orally administered PHAs $(100 \mathrm{mg} / \mathrm{kg}$ body weight) for the suppression of voluntary food consumption in prefasted rats. PHA isolectins (P. vulgaris) were found to exert marked and significant effects. In an investigation in which growing rats were fed for 17 days with a diet containing purified lectins $(0.25 \%$ of the dry matter) from P. vulgaris, the dietary lectins elicited mainly a food intake decrease and extensive alterations of the small intestinal mucosa [17].

It has long been known that the inclusion of raw kidney bean in the diet of experimental animals causes rapid weight loss and the animals may eventually die, and while after heat treatment, these seeds are no longer toxic [18]. The results herein agree with the finding of Pereira et al. [19] who showed that the gavage feeding with white kidney bean flour for 21 days had no effect on the body weight gains of growing rats. However, Jaffé and Lette [20] from the National Institute of Nutrition, Venezuela, mentioned that, in growth experiments, the rats fed the black or red kidney beans with high hemagglutinating activity lost weight rapidly and did not survive with this diet for more than 2 weeks. Herzig et al. [21] reported that the inclusion of $42 \mathrm{mg}$ of PHA in the diet of rats during 10 days generated a significant loss in their body weights. Three intragastric administrations of $400 \mathrm{mg}$ red kidney bean albumin $/ \mathrm{kg}$ body weight (about $100 \mathrm{mg} \mathrm{PHA} / \mathrm{kg}$ body weight) to neonatal suckling piglets at 10,11, and 12 days of life resulted in less body weight gain as compared to controls. Six of the 11 lectin-treated and none of the 16 control pigs showed diarrhea symptoms during the treatment; for lectin-treated pigs, diarrhea stopped within $24 \mathrm{~h}$ in every case [22]

The details described by different authors frequently differ from each other in some aspects. One of the reasons is that the lectins from different varieties or cultivars of one plant species may vary considerably in chemical, physical, and biological aspects. Moreover, different isolectins may exist, and subunit aggregation or dissociation depends on the special experimental used. The information on sugar content is also often inconsistent.

Evidently, large differences in toxicity of lectins have been observed. Compared with the extremely toxic ricin, the $\mathrm{LD}_{50}$ of toxic bean lectin is about 1/1000 times smaller. Some bean cultivars and lectins are known to be nontoxic $[23,24]$. This may be due to the lectin concentration in the seed or to the nature or type of lectins present.

In a relation to specificity, there are at least four clearly distinguishable groups of bean lectins [25]. The most abundant Type A will agglutinate both rabbit and trypsinized cow blood cells. Type B is more active on rabbit than on cow blood. Type $\mathrm{C}$ is specific for cow blood, and Type $\mathrm{D}$ does not agglutinate either but will agglutinate pronase-treated hamster blood. When extracts of the different bean types were tested by injection into mice [25] or by feeding the ground seeds to rats [20], it was established that only the A- and C-type beans were toxic, whereas Types B and D were of low toxicity. Only the toxic beans showed mitogenic activity on human leukocytes $[25,26]$.

An interesting observation revealed by the screening study conducted by Grant et al. [27] was the identification of a variety of P. vulgaris, "Pinto III", which was relatively nontoxic and had a very little reactivity toward most of the erythrocytes except pronase-treated rat cells. When this lectin was isolated and characterized [28], it was found to possess two subunits instead of the usual four subunit characteristics of the common 

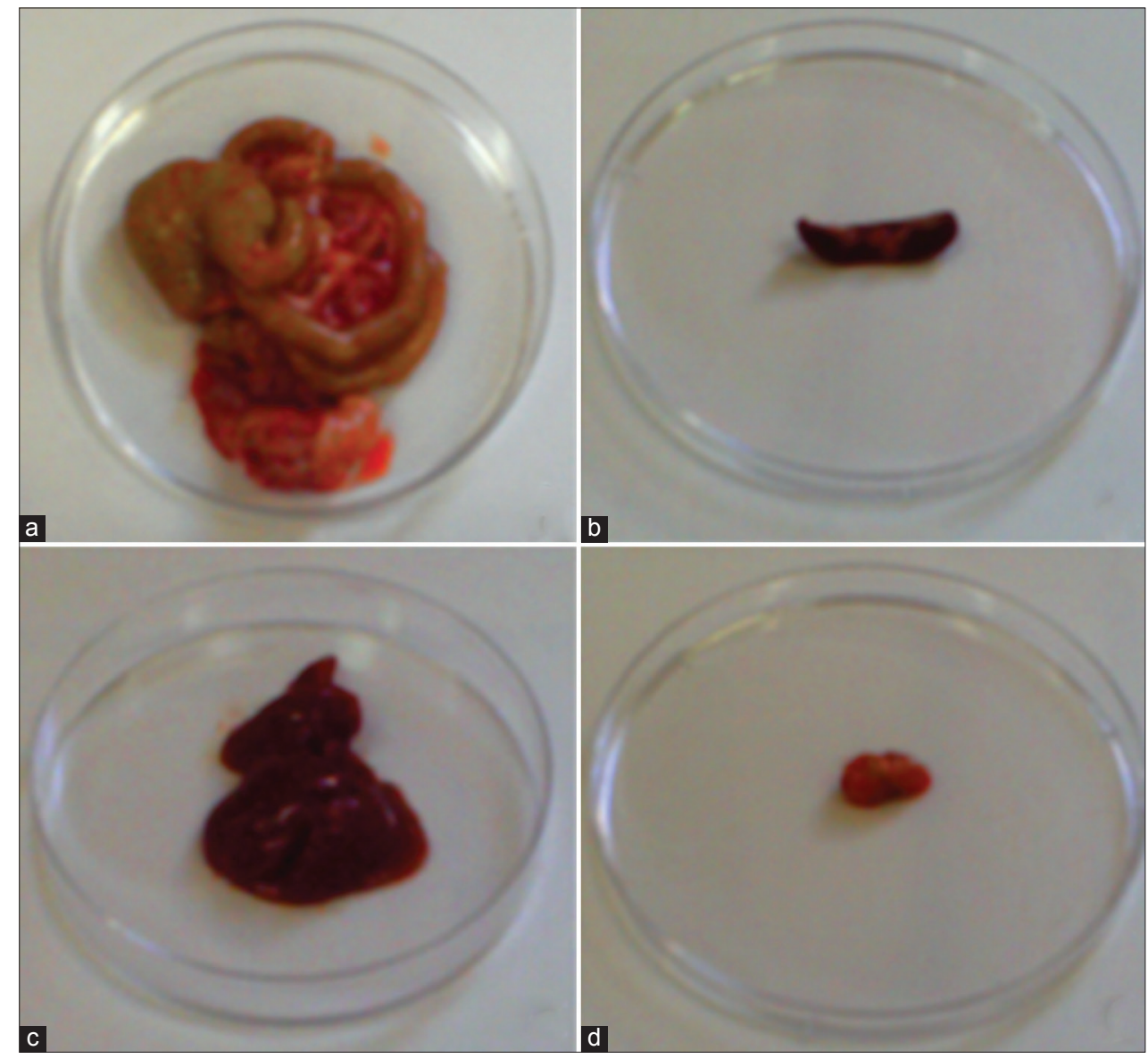

Fig. 4: Physical appearance of some internal organs of Wistar rat gavaged with Beldia bean flour suspension at the dose of $300 \mathrm{mg} / \mathrm{day}$ for 10 days. (a) Small intestine; (b) Spleen; (c) Liver; (d) Thymus

P. vulgaris lectin. A slight immunochemical cross-reaction with the more common $P$. vulgaris lectin was noted. It had been noted earlier [4] that this lectin did not inflict the usual damage to the intestinal mucosa associated with the ingestion of lectins derived from toxic species of $P$. vulgaris. It would appear that the low level of hemagglutinating activity displayed toward most cells and the lack of toxicity of the "Pinto III" bean are a consequence of its lower valency (i.e. , tow subunits instead of four), which would weaken its affinity to cell surfaces.

Pusztai [29] presented evidence suggesting that lectin endocytosis by mucosal cells is a prior step to inducing nutritional toxicity and a whole series of systemic effects thereof, including insulin release [30], mobilization of liver glycogen [31], and immunological response [32] in rats. Atrophy of the thymus [33] and spleen [34] has also been reported when feeding diets with purified Phaseolus lectin or raw beans. Regarding the internal organs weights, the results of this trial showed no effect of Beldia ground beans on the weights of the small intestine, spleen, liver, and thymus compared to the control group. Thus, it can be advanced the following idea that the normal integrity of these organs, associated with a normal growth and normal feed consumption of animals, resulted in remained clinically healthy rats.

Obtained findings confirmed the fact exposed by many investigators that the gastrointestinal tract cannot be affected or reacted morphologically if the concentration of lectins fed to rats is low. For instance, the results obtained here agreed with Pereira et al. [19] who found that the administration by gavage of white bean flour ( $P$. vulgaris) at $1 \mathrm{mg} / \mathrm{g}$ body weight in Wistar rats for 21 days did not alter the weights of the liver and pancreas. In the present investigation, the pancreas was not evaluated. Delgado et al. [35] also reported that the incorporation of beans into the diets of rats did not induce any changes in the liver weight of the rats. In contrast,
De Oliveira et al. [36] stated that, in 10-day pair-feeding experiments, the inclusion of purified kidney bean lectins in egg albuminbased rat diets induced intestinal hypertrophy and hyperplasia, pancreatic enlargement, increased liver weight, thymus atrophy, and a loss of muscle mass. Linderoth et al. [37] indicated that the daily administration of PHA for 3 days through orogastric feeding $(0.05 \mathrm{mg}$ PHA/g body weight) increased gastrointestinal growth of rats. However, parental PHA exposure (0.05 PHA/g body weight), increased liver and spleen weight, and decreased thymus weight. Filip et al. [38] postulated in their paper that the administration of PHA (The stock solution of crude PHA in $0.9 \% \mathrm{NaCl}$, was $(20 \% \mathrm{w} / \mathrm{v})$ in water: $50 \mathrm{mg}$ $\mathrm{PHA} / \mathrm{ml}, 20 \mathrm{ml} / \mathrm{kg}$ body weight) through the stomach tube to rats for 11 days resulted in an increase in the weight of the small intestine ( $p>0.05$ ) (control, $6.6 \mathrm{~g}$, and experimental, $7.9 \mathrm{~g}$ ). Reynoso-Camacho et al. [39] have evaluated, in vivo, the acute toxicity effect of a lectin extracted from tepary bean (Phaseolus acutifolius) on the development of the thymus, kidney, lung, and liver. These researchers reported that the most important anatomical changes produced by tepary lectin were in the thymus and the spleen of rats. The thymus presented a degeneration reflected in a significant decrease in weight. Therefore, they came by a conclusion that this atrophy may be linked to stress or to systemic immunological reactions produced by the lectin. The spleen was found to be greater in size when compared to control. Reynoso-Camacho et al. [39] explained that this significant increase in the weight of the spleen could be due to the enhanced lymphocyte stimulation required by the body's defense system to counteract the intraperitoneal administered tepary lectin. Another possibility could be an increased mitogenic activity of the lectin toward splenocytes. No effects were found in this work on the size of the spleen, liver, and thymus organs that are responsible for the immunological response in rats. The overall response indicates that the immunological organs were normally functional in BBFS-treated rats. 


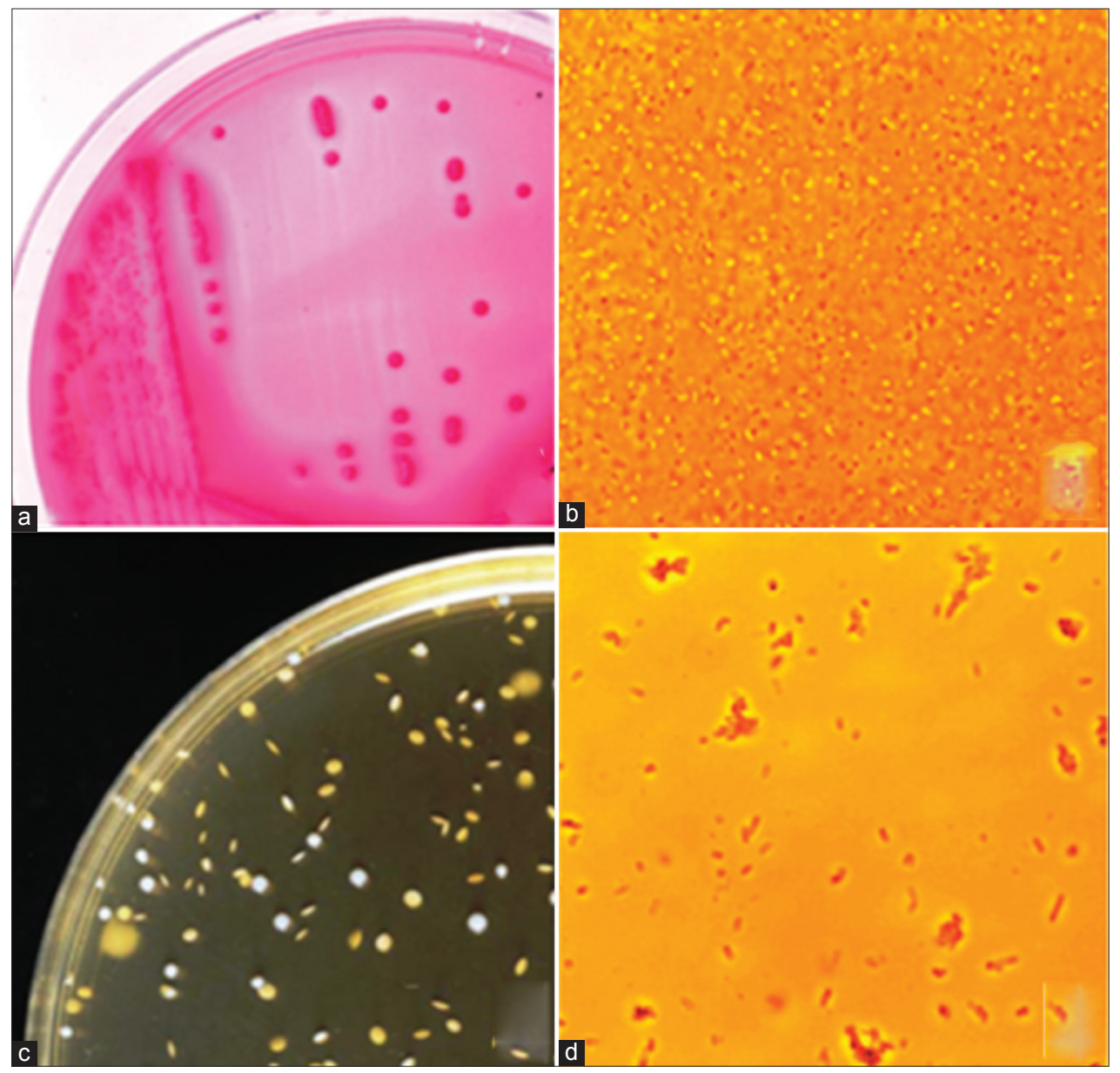

Fig. 5: Fecal coliform and lactobacilli of Wistar rat gavaged with Beldia bean flour suspension at the dose of $300 \mathrm{mg} / \mathrm{day}$ for $10 \mathrm{days}$. (a) Coliform colonies growing on MacConkey agar. Incubated aerobically for $24 \mathrm{~h}$ at $37^{\circ} \mathrm{C}$. (b) Light microscope view of coliform at $40 \times$ magnifications. (c) Lactobacilli colonies growing on MRS broth agar. Incubated anaerobically for $48 \mathrm{~h}$ at $37^{\circ} \mathrm{C}$. (d) Light microscope view of lactobacilli at 40× magnifications

Table 1: Effect of BBFS diet on the relative sizes of individual organs of Wistar rats

\begin{tabular}{lll}
\hline Organ & \multicolumn{1}{c}{ Organ weight } \\
\cline { 2 - 3 } & $\begin{array}{l}\text { Control } \\
\text { rats (RPFS) }\end{array}$ & $\begin{array}{l}\text { Experimental } \\
\text { rats (BBFS) }\end{array}$ \\
\hline Small intestine & $6.00 \pm 0.46$ & $5.52 \pm 0.91^{\dagger}$ \\
Spleen & $0.21 \pm 0.02$ & $0.20 \pm 0.01^{\dagger}$ \\
Liver & $4.42 \pm 0.39$ & $4.47 \pm 0.29^{\dagger}$ \\
Thymus & $0.20 \pm 0.02$ & $0.19 \pm 0.04^{\dagger}$ \\
One group of rats was fed RPFS and a second group BBFS diet (300 mg/3 \\
ml distilled water). After 10 days, the rats were sacrificed, various organs \\
dissected out, and immediately weighted. The weights of organs are expressed \\
in g/100 g body weight. The values are expressed as \pm SEM for 10 rats/group; \\
†Significantly not different from control value (p>0.05; Student's t-test); \\
RPFS: Rodent pellet flour suspension, BBFS: Beldia bean flour suspension. \\
SEM: Standard error mean
\end{tabular}

Previously, PHA has been reported to dose-dependently induce bacterial overgrowth in the intestine, which is associated with weight loss, malabsorption, and villus damage $[2,6,40]$. It has been suggested that PHA increases the turnover of epithelial cells, promoting the expression of mannosylated receptor glycans on the gut surface and thus leading to increased adhesion and subsequent proliferation of mannose-sensitive type 1-fimbriated Escherichia coli. Thus, this factor could aggravate the toxicity exerted by $P$. vulgaris lectins. The raw Beldia bean treatment in this trial had a significant effect on the investigated bacterial groups (e.g., coliforms and lactobacilli) in the feces of rats. Very little literature is available regarding the effect of $P$. vulgaris lectins on the composition of fecal microflora. Somewhat, more information is available on their effects on intestinal microflora. Several researchers have observed increased coliforms and lactobacilli when animals have subjected to a dietary of kidney beans (P. vulgaris L.). Wilson et al. [5] reported that the inclusion in rat diets of raw kidney beans (P. vulgaris variety "Processor") containing high levels of lectins resulted in a dramatic overgrowth of coliforms in the small intestine within $24 \sim 72 \mathrm{~h}$ of feeding, especially Escherichia coli. No overgrowth occurred when the beans fed to rats were of a low lectin variety "Pinto III." Wilson et al. [5] hypothesized that kidney bean lectins may indirectly or directly enhance the virulence of coliform strains either through aggregation and elimination of competitive strains or by agglutination of certain strains of E. coli to one another and to the mucosal surfaces of the gut. Similar observations were obtained by Banwell et al. [7] using purified lectin. The authors reported the effect of PHA on the microflora of the small intestine. They noted that, compared with controls, PHA caused proliferation of a consistent adherent microbial flora in the jejunum. The predominant bacteria identified were E. coli, Streptococcal sp., and Lactobacillus. Recent data pointed out that a gastric gavage of $33 \mathrm{mg}$ of PHA/0.5 ml of $\mathrm{NaCl}$ twice daily during 2 days strongly affected the intestinal and fecal bacteria population structures of Wistar rats [11]. In one side, it was observed that PHA administration led to increased bacterial counts of both $E$. coli and lactobacilli in the small intestine. In other side, it increased as well the numbers of $E$. coli, lactic acid bacteria, and other Enterobacteriaceae in the feces. 
Table 2: HA of human erythrocytes Group 0 with various serum extract dilutions of Wistar rats

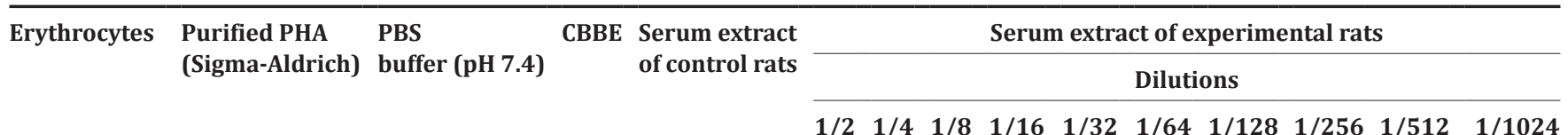

0

-: No agglutination, +: Agglutination; Negative control: Phosphate-buffered saline (PBS; pH 7.4); Positive control: Purified PHA (Sigma-Aldrich, Lesquin, France);

CBBE: Extract obtained after homogenization of $300 \mathrm{mg}$ Beldia bean flour with $3 \mathrm{ml}$ distilled water, centrifugation, and dilution. HA: Hemagglutination assay,

PHA: Phytohemagglutinin, CBBE: Crude Beldia bean extract

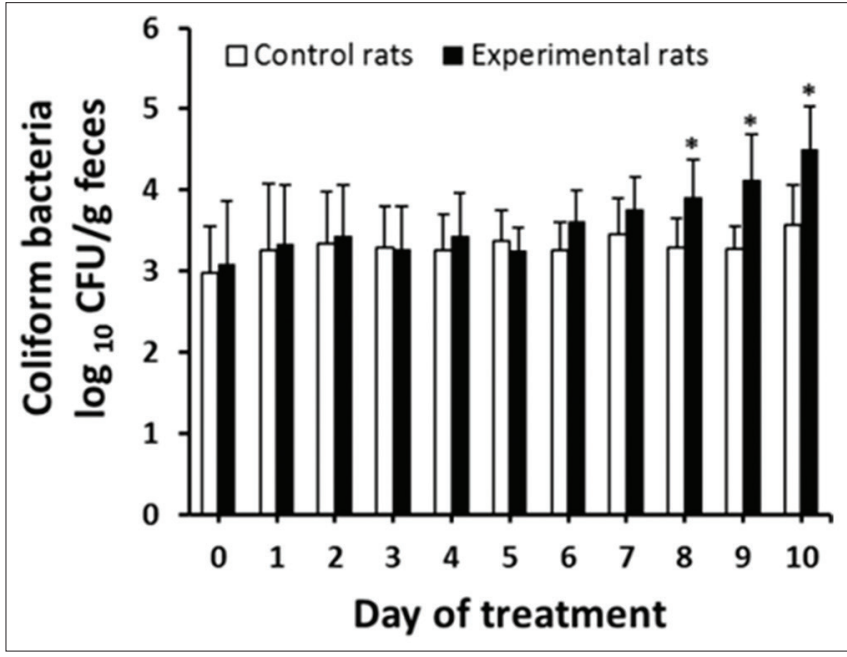

Fig. 6: Counts of fecal coliforms in control rats treated daily with $300 \mathrm{mg}$ rodent pellet flour suspension and in experimental rats gavaged with $\mathbf{3 0 0} \mathrm{mg}$ Beldia bean flour suspension for $\mathbf{1 0}$ consecutive days. Values represent the $\log _{10}$ colony-forming units/g feces expressed as the mean $\pm S E M$; ${ }^{*}$ Significant differences between control and experimental rats were found using t-test $(p<0.05)$

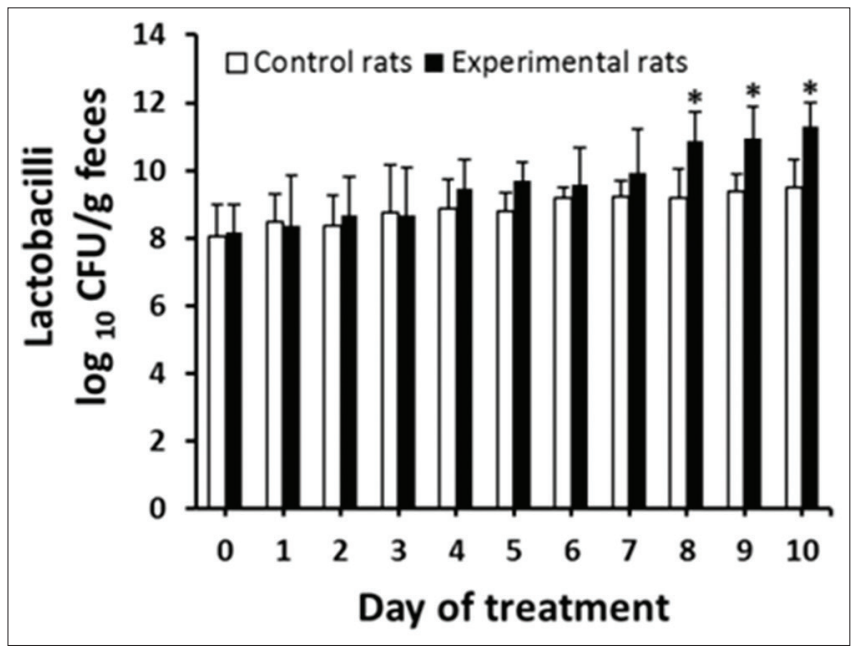

Fig. 7: Counts of fecal lactobacilli in control rats treated daily with $300 \mathrm{mg}$ rodent pellet flour suspension and in experimental rats gavaged with $\mathbf{3 0 0} \mathbf{~ m g}$ Beldia bean flour suspension for $\mathbf{1 0}$ consecutive days. Values represent the $\log _{10}$ colony-forming units/g feces expressed as the mean \pm SEM; *Significant differences between control and experimental rats were found using t-test $(p<0.05)$

The numerous reports stated above clearly indicated that either the addition of raw beans in feed or the administration of purified PHA by gastric intubation to animals could alter the balance of intestinal microflora, by increasing the concentration of pathogenic bacteria such as E. coli, thereby creating a favorable environment for PHAs to manifest their potential toxic effects. The current bacteriological studies, using $300 \mathrm{mg}$ of BBFS for 10 days, have shown a marked influence on the fecal microbial composition of rats. The general suggestion is that the bacterial populations and changes in microbial community are dependent on the dose of PHA fed to animals. Hence, it seems reasonable to assume that $300 \mathrm{mg}$ Beldia flour beans $(\sim 2.76 \mathrm{mg}$ PHA/day) [41] employed in this research were sufficient enough to evoke a bacteriological response in the rat small intestine.

\section{CONCLUSION}

It has been demonstrated here that Wistar rats can tolerate daily intakes of $300 \mathrm{mg}$ of raw Beldia flour beans suspension, without affecting performance. There were no mortalities and no clinical signs considered to be of toxicological significance. Orogastric intubation studies clearly showed that the feed consumption and the body weight gain were similar in rats from control and experimental groups. The weights of the small intestine, spleen, liver, and thymus were not affected through oral administration of white beans. Feeding by gavage of raw beans diet produced significant increases in the counts of fecal coliform and lactobacilli populations. This provides strong evidence of an intraluminal overgrowth of bacteria developed in the small intestine following the ingestion of PHAs, which may partially account for the maldigestion and malabsorption of nutrients. Better understanding of the ecological changes may be achieved by further time-sequence studies of microbial colonization of the intestinal epithelium.

\section{ACKNOWLEDGMENTS}

This work was supported by "Korea-Tunisia joint research Program" grant funded by the Korea Government (ministry of science, ICT and future planning) in 2016 (NRF-2016K1A3A1A09919130).

\section{CONFLICTS OF INTEREST}

The authors declare that they do not have any conflict of interest.

\section{REFERENCES}

1. Pusztai A, Palmer R. Nutritional evaluation of kidney beans (Phaseolus vulgaris): The toxic principle. J Sci Food Agric 1977;28:620-23.

2. Banwell JG, Boldt DH, Meyers J, Weber FL Jr. Phytohemagglutinin derived from red kidney bean (Phaseolus vulgaris): A cause for intestinal malabsorption associated with bacterial overgrowth in the rat. Gastroenterology 1983;84:506-15.

3. Banwell JG, Abramowsky CR, Weber F, Howard R, Boldt DH. Phytohemagglutinin-induced diarrheal disease. Dig Dis Sci 1984:29:921-9.

4. King TP, Pusztai A, Clarke EMW. Kidney bean (Phaseolus vulgaris) lectin-induced lesions in rat small intestine: 1. Light microscope studies. J Comp Pathol 1980;90:585-95.

5. Wilson AB, King TP, Clarke EM, Pusztai A. Kidney bean (Phaseolus vulgaris) lectin-induced lesions in rat small intestine: 2. Microbiological studies. J Comp Pathol 1980;90:597-602.

6. Banwell JG, Howard R, Cooper D, Costerton JW. Intestinal microbial flora after feeding phytohemagglutinin lectins (Phaseolus vulgaris) to rats. Appl Environ Microbiol 1985;50:68-80. 
7. Banwell JG, Howard R, Kabir I, Costerton JW. Bacterial overgrowth by indigenous microflora in the phytohemagglutinin-fed rat. Can $\mathrm{J}$ Microbiol 1988;34:1009-13.

8. Helrich K, editor. AOAC: Official Methods of Analytical Chemists. Vol.1. Arlington, Virginia, USA: Association of Official Analytical Chemists, Inc.; 1990.

9. Weinman MD, Allan CH, Trier JS, Hagen SJ. Repair of microvilli in the rat small intestine after damage with lectins contained in the red kidney bean. Gastroenterology 1989;97:1193-204.

10. Hagen SJ, Trier JS, Dambrauskas R. Exposure of the rat small intestine to raw kidney beans results in reorganization of absorptive cell microvilli. Gastroenterology 1994;106:73-84

11. Gross G, Wildner J, Schonewille A, Rademaker JL, van der Meer R, Snel J. Probiotic Lactobacillus plantarum 299v does not counteract unfavorable phytohemagglutinin-induced changes in the rat intestinal microbiota. Appl Environ Microbiol 2008;74:5244-49.

12. Ellinger DK, Muller LD, Glantz PJ. Influence of feeding fermented colostrum and Lactobacillus acidophilus on fecal flora of dairy claves. J Dairy Sci 1980;63:478-82.

13. Fantini N, Cabras C, Lobina C, Colombo G, Gessa GL, Riva A, et al. Reducing effect of a Phaseolus vulgaris dry extract on food intake, body weight, and glycemia in rats. J Agric Food Chem 2009;57:9316-23.

14. Marzo F, Alonso R, Urdaneta E, Arricibita FJ, Ibáñez F. Nutritional quality of extruded kidney bean (Phaseolus vulgaris L. Var. Pinto) and its effects on growth and skeletal muscle nitrogen fractions in rats. J Anim Sci 2002;80:875-9.

15. Lafont J, Rouanet JM, Gabrion J, Assouad JL, Zambonino Infante JL, Besançon $\mathrm{P}$, et al. Duodenal toxicity of dietary phaseolus vulgaris lectins in the rat: An integrative assay. Digestion 1988;41:83-93.

16. Baintner K, Kiss P, Pfüller U, Bardocz S, Pusztai A. Effect of orally and intraperitoneally administered plant lectins on food consumption of rats. Acta Physiol Hung 2003;90:97-107.

17. Rouanet JM, Lafont J, Chalet M, Creppy A, Besancon P. Effects of dietary kidney bean (Phaseolus vulgaris) lectins in growing rats. Nutr Rep Int 1985;31:237-44.

18. Cheeke PR. Toxicants of plant origin. Vol. 3. In: Proteins and Amino Acids. Boca Raton, Florida: CRC Press, Inc.; 1989.

19. Pereira LL, Pereira CA, de Sousa RV, dos Santos CD, de Moraes CF, Sátiro LC. White bean flour (Phaseolus vulgaris): Therapeutic and toxicological research in wistar rats. J Appl Pharm Sci 2002;2:1-7.

20. Jaffé WG, Lette CL. Heat-labile growth-inhibiting factors in beans (Phaseolus vulgaris). J Nutr 1968;94:203-10.

21. Herzig KH, Bardocz S, Grant G, Nustede R, Fölsch UR, Pusztai A, et al. Red kidney bean lectin is a potent cholecystokinin releasing stimulus in the rat inducing pancreatic growth. Gut 1997;41:333-8.

22. Rådberg K, Biernat M, Linderoth A, Zabielski R, Pierzynowski SG, Weström BR. Enteral exposure to crude red kidney bean lectin induces maturation of the gut in suckling pigs. J Anim Sci 2001;79:2669-78.

23. Jaffé WG, Gómez MJ. Beans of high or low toxicity. Plant Food Hum Nutr 1975;24:359-65.

24. Pusztai A, Clarke EM, King TP, Stewart JC. Nutritional evaluation of kidney beans (Phaseolus vulgaris): chemical composition, lectin content and nutritional value of selected cultivars. J Sci Food Agric 1979; $30: 843-8$

25. Jaffé WG, Brücher O, Palozzo A. Detection of four types of specific phytohemagglutinins in different lines of beans (Phaseolus vulgaris).
Z Immunitatsforsch Exp Klin Immunol 1972;142:439-47.

26. Jaffé WG. Factors affecting the nutritional value of beans. In: Milner M, editor. Nutritional Improvement of Beans. New York: Protein Advisory group of U.N. System; 1973.

27. Grant G, More LJ, McKenzie NH, Stewart JC, Pusztai A. A survey of the nutritional and haemagglutination properties of legume seeds generally available in the UK. Br J Nutr 1983;50:207-14

28. Pusztai A, Grant G, Stewart JC. A new type of Phaseolus vulgaris (cv. Pinto III) seed lectin: Isolation and characterization. Biochim Biophys Acta 1981;671:146-54

29. Pusztai A. Plant Lectins. Cambridge, UK: Cambridge University Press; 1991.

30. Cuatrecasas P, Tell GP. Insulin-like activity of concanavalin A and wheat germ agglutinin - direct interactions with insulin receptors. Proc Natl Acad Sci U S A 1973;70:485-9.

31. Grant G, de Oliveira JT, Dorward PM, Annand MG, Waldron M, Pusztai A. Metabolic and hormonal changes in rats resulting from consumption of kidney bean (Phaseolus vulgaris) or soybean (Glycine max). Nutr Rep Int 1987;36:763-72.

32. Pusztai A, Greer F, Lima MD, Prouvost-Danon A, King TP. Local and systemic responses to dietary lectins. In: Goldstein IJ, Etzler ME, editors. Chemical Taxonomy, Molecular Biology and Function of Plant Lectins. New York, NY: Alan R. Liss, Inc.; 1983. p. 271-72.

33. Oliveira JT, Vasconcelos IM, Gondim MJ, Cavada BS, Moreira RA, Santos CF, et al. Canavalia brasiliensis seeds. Protein quality and nutritional implications of dietary lectin. J Sci Food Agric 1994;64:417-24.

34. Greer F, Brewer AC, Pusztai A. Effect of kidney bean (Phaseolus vulgaris) toxin on tissue weight and composition and some metabolic functions of rats. Br J Nutr 1985;54:95-103.

35. Delgado E, Vences-Montaño MI, Rodríguez JV, Rocha-Guzman N, Rodriguez-Vidal A, Herrera-Gonzalez SM, et al. Inhibition of the growth of rats by extruded snacks from bean (Phaseolus vulgaris) and corn (Zea mays). Emir J Food Agric 2012;24:255-63.

36. De Oliveira JT, Pusztai A, Grant G. Changes in organs and tissues induced by feeding of purified kidney bean (Phaseolus vulgaris) lectins. Nutr Res 1988;8:943-47.

37. Linderoth A, Prykhod'ko O, Pierzynowski SG, Weström BR. Enterally but not parenterally administered Phaseolus vulgaris lectin induces growth and precocious maturation of the gut in suckling rats. Biol Neonate 2006;89:60-8.

38. Filip R, Wdowiak L, Harrison AP, Pierzynowski SG. Dietary supplementation with phytohemagglutinin in combination with $\alpha$-ketoglutarate limits the excretion of nitrogen via urinary tract. Ann Agric Environ Med 2008;15:309-15.

39. Reynoso-Camacho R, González de Mejía E, Loarca-Piña G. Purification and acute toxicity of a lectin extracted from tepary bean (Phaseolus acutifolius). Food Chem Toxicol 2003;41:21-7.

40. Nciri N, Cho N, Bergaoui N, El Mhamdi F, Ben Ammar A, Trabelsi N, et al. Effect of white kidney beans (Phaseolus vulgaris L. Var. Beldia) on small intestine morphology and function in wistar rats. J Med Food 2015;18:1387-99.

41. Nciri N, Cho N, El Mhamdi F, Ben Ismail H, Ben Mansour A, Sassi FH, et al. Toxicity assessment of common beans (Phaseolus vulgaris L.) widely consumed by tunisian population. J Med Food 2015;18:1049-64. 